\title{
O EGO VS O ECO: UMA VISÃO SOBRE O PRINCÍPIO RESPONSABILIDADE DE HANS JONAS
}

\section{Nícolas de Souza Brandão de Figueiredo; Rosemar de Fátima Vestena ${ }^{2}$; Marcos Alexandre Alves ${ }^{3}$}

\section{Resumo}

Ao longo da segunda metade do século $X X$ o filósofo alemão Hans Jonas desenvolveu sua epistemologia baseada em suas experiências vividas em duas guerras mundiais, tragédias ambientais decorrentes do uso errado de tecnologias nucleares. O artigo, partindo das ideias de Jonas e fundamnetado no Princípio Responsabilidade, examina alguns questionamentos a cerca de como a sociedade humana se estabelece, como suas religiões e sua ciência impactaram seu modo de perceber a própria espécie em relação com a natureza. Examina-se ainda, como que uma distorção nos pensamentos científicos e teológicos dissociaram o homem da natureza, fazendo com que não se visse parte do Eco, elevando seu Ego, como que o ensino de ciências unido do turismo pedagógico pode contornar esta dissociação, aproximando alunos dos conteúdos de ecologia.

Palavras-chave: Ensino de Ciências, Turismo Pedagógico, Ensino de Ecologia, Espaços não formais de Ensino, Epistemologia da Ciência.

Eixo Temático: Educação, Cultura e Comunicação (ECC).

\section{INTRODUÇÃO}

Este texto tem sua origem em uma atividade da disciplina de Fundamentos Epistemológicos da Ciência, do Programa de Pós Graduação em Ensino de Ciências e Matemática da Universidade Franciscana de Santa Maria, Rio Grande do Sul, Brasil. Ao longo da referida disciplina, foram debatidos autores como: Edgar Morin, filósofo francês que nos traz reflexões sobre o erro de uma visão cartesiana e do pensamento de Descartes, que ao dissociar o ser pensador do objeto a ser pensado, homem x natureza, coloca o homem como um não-ser animal, ao invés de

\footnotetext{
${ }^{1}$ Doutorando em Ensino de Ciências e Matemática (PPGECIMAT), Universidade Franciscana - UFN. E-mail: nicolas.figueiredo@ufn.com.br

2 Doutora e Professora no Programa de Ensino de Ciências e Matemática, (PPGECIMAT), Universidade Franciscana - UFN. E-mail: rosemarvestena@gmail.com

${ }^{3}$ Doutor e Professor no Programa de Ensino de Ciências e Matemática, (PPGECIMAT), Universidade Franciscana - UFN. E-mail: maralexalves@gmail.com.
} 
um ser animal e natural; e Zygmunt Bauman, filósofo alemão que aborda a liquefação da sociedade após a segunda guerra mundial, e como esta liquefação social impacta a produção, as relações e o ensino. Outro filósofo que, assim como Morin e Bauman, forjou seus pensamentos ao longo de duas guerras, e dos efeitos sociais da Solução Final de Adolf Hitler, geradora do Holocausto, foi o filósofo alemão Hanz Jonas.

Jonas foi escolhido como referência para este texto, parte introdutória da tese de doutorado do primeiro autor deste trabalho, por ter uma temática ambiental, e da responsabilidade da espécie Homo sapiens sapiens (ser-humano) para com as demais espécies, e para com seu habitat natural, o planeta Terra. Esta temática, que centralmente, se liga à temática da referida tese, juntamente com temas correlatos, como: o Ensino de Ciências, Formação Docente e práticas educativas lúdicas de interpretação ambiental presentes no Turismo Pedagógico.

\section{A TRANSANIMALIDADE DO Homo sapiens sapiens E SUA RESPONSABILIDADE}

Jonas, de origem judaica, nasceu no início do século XX, em 1903, na cidade de Mönchengladbach. Sua ascendência o fez ingressar nos movimentos sionistas da segunda metade do século XX. Jonas, ainda nos anos da década de 1920, pós horrores de uma Primeira Guerra Mundial, ingressou no meio acadêmico para cursar filosofia, sendo contemporâneo e colega de Hannah Harent, importante filósofa alemã que abordou a banalidade do mal.

Com a ascendência do regime antissemita na Alemanha, Hanz Jonas saiu de seu país, em 1933, e passou a ter, em suas temáticas, após o Holocausto, onde perdera sua mãe, no campo de concentração e extermínio de Auschwitz - Polônia, questões relacionadas à: bioética (temática decorrente dos experimentos nazistas com humanos); responsabilidade tecnológica (reflexões que o autor teve após as bombas atômicas de Hiroshima e Nagasaki - Japão; e da tragédia nuclear de Chernobyl - União Soviética, hoje Ucrânia); e o colapso ambiental (gerado por um sistema mundial de lucro e consumo, o capitalismo). 
Esta temática ambiental está mais fortemente presente em sua principal obra, base para trabalhos e pensamentos ambientais alemães, $O$ Princípio Responsabilidade, publicado em 1979. Jonas também publicou trabalhos de extrema relevância para a construção de uma bioética estado-unidense, local onde morou até seu falecimento, em 1993, dentre eles destaca-se o Fenômeno da Vida: fundamentos para uma biologia filosófica, de 1966 (JONAS, 2004).

Tendo em vista os pensamentos de Hans Jonas, especialmente aqueles presentes em o Princípio Responsabilidade, trazemos uma visão de como ocorreu a relação de nossa espécie com a observação de outras espécies; como foi a construção de religiões; e como uma visão distorcida de pensamentos teológicos e de pensamentos científicos, causada pela não compreensão de nossa própria transanimalidade, gera um caos ambiental, colocando, assim, em risco nossa própria existência.

Nossa espécie, ao não se perceber transanimal, ou seja, ainda que pensante, consciente de sua própria consciência e capaz, cognitivamente, de perceber e utilizar o meio de forma inovadora, ainda é apenas mais uma espécie dentre tantas outras, porém com um conhecimento gerador de responsabilidades. Assim, o homem, ao não se percebe como espécie animal, não se vê como parte do ECO, elevando, seu EGO, e colocando-se, assim, em papel de superioridade, subjugando espécies e esgotando recursos em nome de seu progresso, sem perceber o retrocesso gerado por esta visão dualista, positivista e excludente.

\section{O EDUCADOR COMO MEDIADOR DO PODER DO CONHECIMENTO}

Tendo isto posto, pretendemos abordar que esta situação de caos ambiental só pode ser revertida a partir de um poder libertador, o conhecimento. Este poder somente pode ser gerado através de uma alfabetização libertadora, e de um letramento científico capazes de formar e desenvolver cidadãos pensantes e críticos (CHASSOT, 2003; SASSERON; CARVALHO, 2011). Desta forma, educadores precisam ensinar seus educandos a aprender, e se verem parte do ECO, para que possam diminuir seus EGOS. Deste modo, podem tomar consciência de serem 
seres orgânicos naturais e livres, assim como quaisquer outro indivíduo de quaisquer outra espécie, também orgânica naturalmente livre e evolutiva. Porém, para que isto seja possível, é preciso que estes educadores recebam uma formação que os capacite para que utilizem as mais diversas potencialidades didáticas. Desntre elas se têm os espaços não formais de ensino (ENFE), desde que estejam unidos dos espaços formais de ensino (EFE), a sala de aula, seja de forma presencial ou de forma remota (MARANDINO, 2005).

Desta maneira, ao se utilizar de atividades lúdicas inerentes aos ENFE, como museus de história natural e unidades de conservação, o professor, em parceria com profissionais do turismo, pode fazer uso de uma importante ferramenta de ensino, o Turismo Pedagógico (TP). O TP é uma sub-segmentação turística, pertencente à segmentação do Turismo e Ensino e Intercâmbio, voltada ao ensino, e habilitada para realizar atividades de ecoturismo de forma lúdica gerando uma interpretação ambiental (SANTOS et al., 2020). Desta forma, o educando é capaz de perceber sua própria transanimalidade, se ver parte do ECO, criar afeto pelo meio que o cerca e perceber o valor ambiental, compreender normas ambientais e mudar atitudes ambientais.

\subsection{A dualidade, homem $x$ animais/natureza}

Ao longo de sua história, o ser-humano, vem demonstrando um grande interesse em observar e compreender os hábitos e comportamentos das demais espécies animais. Em seus primórdios, este interesse foi representado por pinturas rupestres, que retratam eventos de caças e pesca, e bandos de grandes animais. Estas pinturas eram feitas nas paredes de cavernas presentes em locais como Brasil e França (JUSTAMAD et al., 2020). Posteriormente, com a estabilização de sociedades, elementos naturais passaram a ser vistos com seres divinos, tendo suas representações esboçadas e imaginadas em figuras de Deuses antropomórficos, em culturas politeístas, como no antigo Egito, através da imagem de Hórus, o Deus Falcão (PORTER, 2011), ou na América pré-colombiana, pela imagem de Quetzalcoatl, a deusa asteca em forma de serpente emplumada (PÉREZ-ZAVALA et al., 2020). 
Conforme as sociedades humanas foram se desenvolvendo diversos elementos da fauna e flora foram sendo incorporados na cultura popular, tornando-se seres mitológicos. Desta forma, elementos faunísticos, foram representados no folclore e na mitologia de todos os continentes, como as Harpias, na Grécia. Estas, eram poderosos seres com corpo de mulher, e asas e pés de aves de rapina (TONKS, 1907); ou a Jorogumo, presente na mitologia japonesa. Este ser seria uma aranha que se transforma em mulher para atrair suas presas humanas, (ABBA, 2016).

No continente sul-americano, não são raras as lendas e contos de povos indígenas que retratam a flora local, como por exemplo, a lenda amazônica da vitória-régia (BRAGA et al., 2019). Por sua vez, no sul do Brasil, elementos faunísticos também estão presentes na mitologia Guarani e Kaingang, através de seres como: tamanduá-mirim, urubu, sapo-cururu e o Maino'i, um beija-flor responsável pela criação do universo (MANDURUKU, 1964).

Entretanto, a partir de uma visão monoteísta, com um único Deus criador, o homem passou a ter um papel centralizado, como sendo a obra mais perfeita deste Deus. Nesta visão, o homem foi concebido de forma dívida, à sua imagem e semelhança, e a partir de erros interpretativos desta visão, se dissocia o homem dos animais, da própria natureza, que está ali apenas para serví-lo. Em uma visão não metafísica e espiritual, também houve este distanciamento do homem e do natural, neste caso, uma visão dualista, baconiana em que o homem, por ser racional e ter consciência de sua própria racionalidade, eleva seu ego. Com isso, se tem uma visão distorcida da Origem das Espécies, a teoria Evolutiva de Charles Darwin (DARWIN, 2009). Nesta visão distorcida, se a evolução é um fato, e o Homem, é o ser mais evoluído, as demais espécies tornam-se apenas animais e não seres orgânicos livres.

Apesar de todo esse interesse pelo meio natural, somente nos últimos séculos, entre o século XVIII e segunda metade século $X X$, é que foram concebidos campos específicos do conhecimento, que buscassem abordar estes assuntos. Desntre eles temos, a História Natural, e sua sucessora, a Biologia, e mais recentemente a Ecologia, década de 1970. Este último, se tornou um campo da ciência que visa compreender e explicar de que forma os elementos abióticos, como elementos 
químicos e fenômenos físico-químicos, se relacionam com os elementos bióticos, como animais e plantas, bem como a maneira com que elementos bióticos se relacionam entre si (NUCCI, 2007).

\subsection{O primeiro poder: o conhecimento do Eco}

A partir desta tomada de consciência, sobre as relações ecológicas, podemos traçar um paralelo com o primeiro dos três poderes abordados por Hanz Jonas, o poder do conhecimento, o ter conhecimento do próprio conhecimento. Neste ponto, nossa espécie tomou conhecimento de que existem inúmeras relações entre os seres vivos e o ambiente. Um exemplo destas relações são as alterações no solo, como a escavação de tocas feitas por aves como a Athene cunicularia (corujaburaqueira; SICK, 2001), ou ainda o Euphractus sexcinctus (tatu-peba). Ao escavar sua toca, estes animais permitem a entrada de luz, em uma parte do solo que antes não tinha contato direto com a luz solar, alterando sua umidade e temperatura (BELTHOLFF; KING, 2002). Ao observar o comportamento destes animais, tribos indígenas, como os Kaingang, podem ter aprendido a construir suas casas subterrâneas (D'ANGELLIS; VEIGA 2003). Outro exemplo são as plantas de metabolismo fotossintético $\mathrm{C} 4$, representadas, por exemplo, por espécies de gramíneas de grande importância econômica e histórico-cultural, como o Zea mays (milho), (ROSSETTO, 2015). Estas espécies têm uma elevada produção de biomassa em curto espaço de tempo, disponibilizando ao meio maiores quantidades de carbono.

Dentro das relações ecológicas entre elementos bióticos, temos a relação presapredador, em que uma Cavia aperea (preá - Rodontia) poderá servir de alimento para um Lycalopex gymnocercus (graxaim-do-campo - Carnívora; CANEL et al. 2016). Outra exemplificação, são as relações mutualistas entre planta-polinizador, como as relações entre abelhas e plantas. Abelhas, com a exótica, no Brasil, Apis mellifera (abelha-doméstica), ou as nativas Plebia spp. (mirins), ao buscarem os seus alimentos nas flores, entram em contato com o pólen e realizam a polinização de plantas, como a maria-mole, Senecio brasiliensis Less (Asteraceae; SOLERA et 
al. 2007). Somente quando o H. s. sapiens começou a compreender estas simples relações entre animais e plantas, a espécie humana passou de uma espécie caçadora-coletora para uma espécie agropastoril (PRISTA, 2012).

\subsection{O segundo poder: o poder sobre o poder}

A partir de então, o homem, passou a realizar interações interespecíficas de novas maneiras, cultivando e auxiliando plantas em seus processos reprodutivo, como a relação que se estabeleceu entre povos italianos e a Vitis vinifera (videira), para a produção de sucos e vinhos (WALDMAN, 2006), e do Z. mays para a produção da polenta. Além disso, nossa espécie também passou a desenvolver relações como o comensalismo, em que urubus (Cathartiformes - Cathartidae) e o Canis lupus familiares (cão-doméstico) passaram consumir os restos alimentares dos humanos (NOVAES; ALVAREZ, 2014). Desta forma, com as interações interespecíficas entre homens e plantas, e entre homens e demais espécies animais, aspectos histórico-culturais, e socioeconômicos típicos de cada região habitada, e de cada sociedade estabelecida, foram sendo desenvolvidos (WALDMAN, 2006).

É importante destacar que os conceitos ecológicos não necessariamente se restringem a apenas a relação entre dois indivíduos ou entre um indivíduo e o meio abiótico que diretamente o cerca. Alguns conceitos estão ligados às questões de macro escala, que envolvem complexas relações comunitárias, populacionais e ecossistêmicas. Neste caso, têm-se conceitos como o nicho trófico (posição ou espaço que uma espécie ocupa na cadeia alimentar); nicho ecológico, que segundo Hutchinson (1978), seria um espaço, um hipervolume que irá descrever as condições e os recursos que permitirão que uma espécie se estabeleça dentro de uma determinada comunidade; e padrões estruturais das redes de interações ecológicas. Isto é, como as espécies se conectam, qual espécie interage com qual, e qual o formato do mosaico de relações (ALBERT; BARABÁSI, 2002).

Entretanto, quando se restringe à compreensão das relações ecológicas entre espécies ou entre indivíduos, em uma micro escala, como as relações mutualistas, ou de presa-predador, não se tem a percepção de que esta interação pode ter um 
efeito negativo a nível populacional, comunitário ou ecossistêmico. Ao interagir de uma forma harmônica com o C. I. familiaris pode-se introduzir uma espécie exótica com potencial de causar perda de indivíduos de diversas espécies nativas (GALETTI, 2006). Portanto, quando há falhas no processo de ensino e aprendizagem, e consequentemente na compreensão da importância de tais conceitos ecológicos, não se percebe que ações cotidianas podem causar alterações nos mais diversos padrões ecológicos.

Neste mesmo sentido, não se compreende os danos ambientais gerados ao se realizar a conversão de solos para a implementação de monoculturas ou da extração de solos para atividades mineradores, e desmatamentos de florestas, como vem se intensificando na Floresta Amazônica Brasileira. Estas ações, na região Norte do Brasil, podem gerar um clima mais seco no Centro-Oeste e no Sudeste do Brasil, causando queimadas mais intensas e alterações nos ciclos de chuva, levando a um colapso hídrico e energético nas regiões mais produtoras e populosas do país.

Neste momento temos o que Hans Jonas descreve como o poder secundário. Neste caso, ao perceber que se tem conhecimento para subjugar outras espécies, e a necessidade de mais poder de consumo, o homem passou a desenvolver novas tecnologias para suprir suas necessidades. Com isso, passou a consumir, de forma cada vez mais acelerada, os recursos naturais em prol de um falso progresso, que promete condições cada vez melhores, mas apenas para aqueles que podem adquirir tais condições.

Para além destas alterações ambientais, em padrões ecológicos, nossa espécie, perdida no segundo poder, citado por Jonas, não percebe que coloca em risco aspectos socioeconômicos, histórico-naturais e culturais que se estabeleceram ao longo de milênios. Desta forma, coloca-se em risco de extinção não apenas espécies animais, mas também a cultura e a história de povos vulneráveis, como pequenas comunidades de imigrantes, populações indígenas, povos ribeirinhos e quilombolas.

\subsection{O terceiro poder: um conhecimento libertador e gerador de responsabilidade}


Assim sendo, de acordo com Hanz Jonas, neste ponto é necessário que um poder terciário aja. Este poder, aqui consideramos como sendo o poder do ensino, de uma alfabetização ecológica libertadora. Consequentemente, somente a partir da compreensão de que unicamente será possível evitar o colapso ecossistêmico, e de nossa própria existência, através de um efetivo um letramento científico (LC; SASSERON 2015).

O LC é um recurso pedagógico que busca um ensino de ciências através de atividades didáticas que coloquem o educando em contato com saberes que afetam o desenvolvimento do conhecimento científico (COUTINHO et al, 2019). Para além da realização destas atividades, nos EFE, isto é, sala de aula, têm-se a realização destas em ENFE. Dentre as possibilidades educativas estão as atividades turísticas da segmentação do turismo pedagógico em ambiente rural, natural ou didáticocientífico (museus). O ecoturismo, o turismo rural e as visitas técnicas aos museus proporcionam atividades com grande potencial de ludicidade, como trilhas ecológicas e experiência de vivência, e interatividade com diversos objetos multidisciplinares que se tornam uma forma prazerosa de ensinar e aprender.

Entretanto, estas atividades somente serão efetivas caso os educadores estejam preparados para unir os conhecimentos teóricos da sala de aula com os conhecimentos práticos dos parques, museus, praças, e serem capazes de trabalhar em conjunto de profissionais também preparados e capacitados do turismo. Com isso, educadores poderão transpor, de forma lúdica, o conhecimento científico, formando, assim, cidadão críticos capazes de reconhecer os valores ambientais, compreender as normas ambientais e mudar as atitudes ambientais da sociedade.

\section{CONSIDERAÇÕES FINAIS}

Neste texto foram abordados aspectos da epistemologia de Hanz Jonas e como sua origem e vivências traumáticas de duas guerras mundiais, tragédias ambientais e humanitárias, causadas pelo uso errado de tecnologias, bem como o modo de vida de sociedades humanas pós-solidez social moldaram os pensamentos, deste 
importante filósofo alemão, acerca de questões humanitárias, tecnológicas e ambientais. A partir das ideias de Jonas, dispostas em três poderes, presentes no Princípio Responsabilidades, traçamos um paralelo de como ocorreu o desenvolvimento do interesse humano por questões ambientais, e como perdemos o controle sobre o poder secundário.

Além disto, trouxemos uma visão de como podemos, através do ensino de ciências, assumir o poder terciário, citado por Hanz Jonas. Este poder, somente poderá, quiçá um dia, ser atingido através de um efetivo ensino de ciências, que una tanto a teoria aprendida em sala de aula, quanto às práticas lúdicas presentes em atividades de turismo pedagógico, como a interpretação ambiental. Desta forma, poderá se formar cidadão críticos, pensantes e ambientalmente responsáveis.

\section{Referências}

ABBA, A. Transcending Cultural Boundary: Renegotiating the Significance of the Spider Folktale. Journal of Literature, Languages and Linguistics. v. 27, 2016, p. 22-26.

ALBERT, R.; BARABÁSI, A. L. Statistical mechanics of complex networks. Reviews of Modern Physics, Ridge, v. 74, n. 1. 47-97. 2002

BELTHOFF, J. R.; KING, R. A. Nest-site characteristics of Burrowing Owls (Athene cunicularia) in the Snake River Birds of Prey National Conservation Area, Idaho, and application to artificial burrow installation. Western North American Naturalis, Boise, v. 62, n. 1, p. 112-119. 2002.

BRAGA, W. S.; PINTO, S. R. L.; QUARESMA, L. C. A. Saberes da cultura amazônica: a lenda da vitória régia no contexto da alfabetização. Brazilian Journal of Development.

v. 5 , n. 12,2019 , p. 32856-32866.

CANEL, D.; SCIOSCIA, N. P.; DENEGRI, G. M.; KITTLEIN, M. Dieta del zorro gris pampeano (Lycalopex gymnocercus) en la província de Bueno Aires. Mastozoología Neotropical, Mendoza, v. 23, p. 359-370. 2016.

CHASSOT, A. Alfabetização científica: uma possibilidade para a inclusão social. Revista Brasileira de Educação. v. 22, p. 89-100. 2003.

COUTINHO, C. RUPPENTHAL, R., OSORIO, T. R. Alfabetização científica na formação de Ciências da Natureza. Intercambios, Dilemas y Transiciones de la Educación Superior, v. 6, p. 1-11, 2019. 
D’ANGELLIS, W. R.; VEIGA, J. Habitação e Acampamentos Kaingang hoje e no passado. Cadernos do CEOM. v. 18, 2003, p. 213-242.

DARWIN, C. A origem das espécies por meio da seleção natural. São Paulo: Escala, 2009. 462 p.

GALETTI, M.; SAZIMA, I. Impacto de cães ferais em um fragmento urbano de Floresta Atlântica no sudeste do Brasil. Natureza \& Conservação, Goiânia, v. 4, n. 1, p. 58-63. 2006.

HUTCHINSON, G. E. An introduction to population ecology. 1 ed. Hardcover, 1978

JONAS, H. O princípio vida: fundamentos para uma biologia filosófica. Petrópolis: Vozes, 2004.

JONAS, H. O princípio responsabilidade: ensaio de uma ética para a civilização tecnológica. Rio de Janeiro: Contraponto: Ed. PUC-Rio, 2006.

JUSTAMAD, M.; OLIVEIRA, G. F.; ALMEIDA, V. J. R.; JÚNIOR, V. S.; QUEIROZ, A. N.; SILVA, V. B; FILHO, A. S. G. Os caçadores da pré-história nas pinturas rupestres do parque nacional Serra da Capivara - Piauí, Brasil. Memória em Rede. v. 12, n. 23, 2020. p. 274-297.

MANDURUKU, D. Contos indígenas brasileiros. $2^{\underline{a}}$ ed. São Paulo - Global, 1964, $64 \mathrm{p}$.

MARANDINO, M. A pesquisa educacional e a produção de saberes nos museus de ciências. História, Ciência, Saúde - Manguinhos, v. 2. (suplemento). 2005.

NOVAES, W. G.; ALVAREZ, M. R. D. V. Relação entre resíduo sólido urbano e urubus-de-cabeça-preta (Coragyps atratus): um perigo as aeronaves no Aeroporto de llhéus (SBIL). Revista Conexão Sipaer. v. 5, n. 1, p. 22-29. 2014.

$\mathrm{NUCCl}, \mathrm{J}$. C. Origem e desenvolvimento da ecologia e da ecologia da paisagem. Revista Eletrônica Geografar, Curitiba, v. 2, n. 1, p. 77-99, 2007.

PÉREZ-ZAVALA, M. D. L.; HERNANDÉZ-ARZABA, J. C.; BISDESHI, D. K.; BARBOZA-CORONA, J. E. Agave: a natural renewable resource with multiple applications. Agave: A natural renewable resource with multiple applications. Journal of the Science of Food and Agriculture. doi:10.1002/jsfa.10586.2020.

PRISTA, A. Sedentarismo, urbanização e transição epidemiológica. Revista Científica da Universidade Eduardo Mondlane, Série: Ciências Biomédicas e Saúde Pública, v. 1, n. 0, p 28-32. 2012.

PORTER, R. Insights into Egyptian Horus Falcon Imagery by Way of Real Falcons and Horus Falcon Influence in the Aegean in the Middle Bronze Age: Part I. Journal of Ancient Egyptian Interconnections. v. 3, n.3, 2011, p. 27-38.

ROSSETTO, J. Caracterização do valor nutritivo e cinética de produção de gases in vitro das espécies de ocorrência no bioma Pampa. 2015. Dissertação (Mestrado em Zootecnia) - Faculdade de Agronomia, Universidade Federal de Santa Maria, Santa Maria, 2015. 
SANTOS, K. F.; CARVALHO, E. T.; HERRERA, M. R. G. A Interpretação Ambiental na Perspectiva dos Projetos do Departamento de Extensão do Instituto Federal de Mato Grosso Campus Cáceres. Dialnet. v.9, n. 6, 2020. http://dx.doi.org/10.33448/rsd-v9i6.3419

SASSERON, L. H.; CARVALHO, A. M. P. Alfabetização científica: uma revisão bibliográfica. Investigações em Ensino de Ciências. v. 16, n. 1, p. 59-77. 2011.

SICK, H. Ornitologia Brasileira. 3 ed. Rio de Janeiro: Editora Nova Fronteira, 2001. $910 \mathrm{p}$.

SOLERA, M.; HEFLER, S. M.; DE PAULA, M. C. Z. Estudo das interações entre insetos e Senecio brasiliensis Less. (Asteraceae) em área experimental no campus da Pontifícia Universidade Católica do Paraná, Toledo, Brasil. Estudos de Biologia, v. 29, n. 66, p. 81-87. 2007.

TONKS, O. S. (1907). An Interpretation of the So-Called Harpy Tomb. American Journal of Archaeology. v. 11, n. 3, 1907, p 321-338.

WALDMAN, M. Meio ambiente \& antropologia, 1 ed. São Paulo: Editora Senac, 2006. 